\title{
Comparative Bench Study Evaluation of a Modified Snorkeling Mask Used During COVID-19 Pandemia and Standard Interfaces for Non-invasive Ventilation.
}

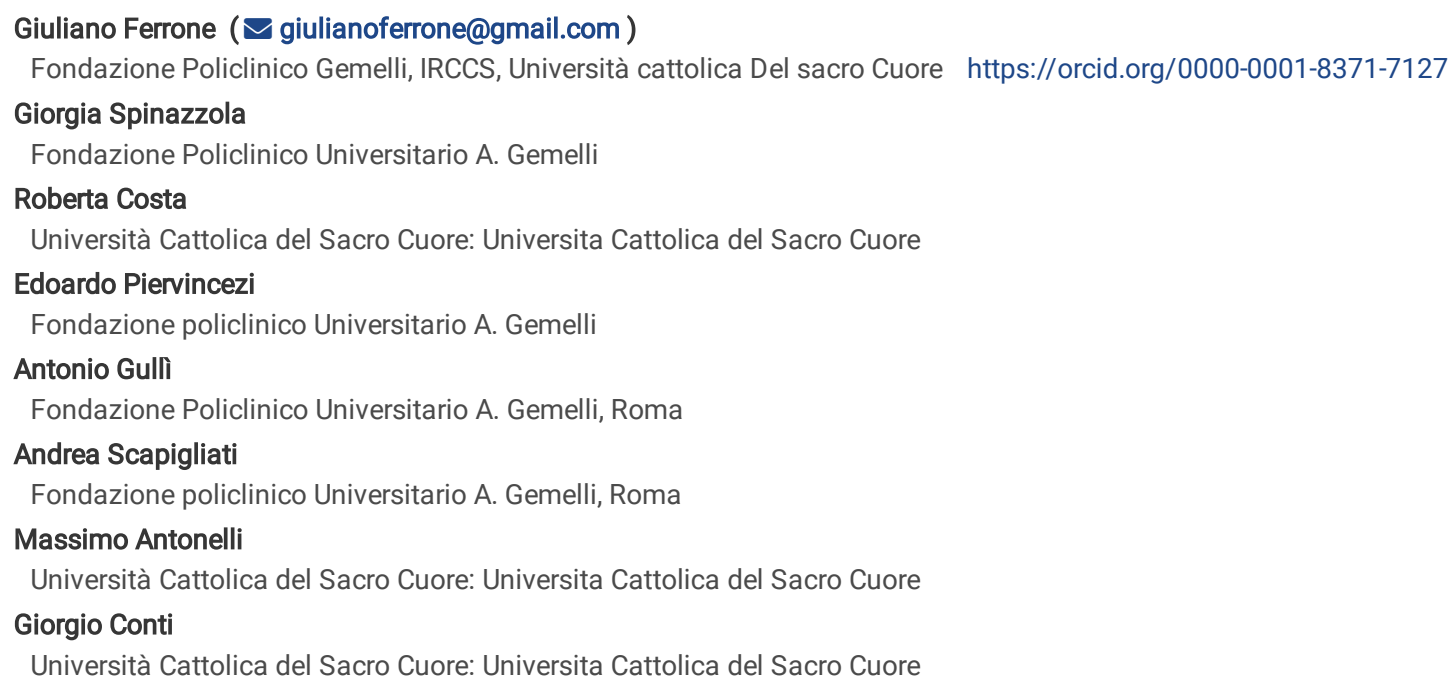




\section{Abstract}

Background

COVID-19 infection has put enormous pressure on the healthcare systems worldwide and especially on Intensive Care Units (ICUs). In this particular situation, a modified snorkeling mask into a mask for non-invasive continuous positive airway pressure (nCPAP) and non-invasive ventilation (NIV), with the help of 3D printers, has been proposed for clinical use. We designed a bench study to compare a Helmet (H), a Full face mask (RFF) and a modified full face snorkeling mask (MFF) for delivering nCPAP and NIV in pressure support mode (PSV).

Methods

A mannequin was connected to an active lung simulator. The inspiratory and expiratory variations in airways pressure observed with a high simulated effort (Pmus), were determined relative to the preset CPAP level. NIV was applied in PSV at two simulated respiratory rates and two cycling-off flow thresholds. During the bench study we measured the variables defining patient-ventilator interaction and performance.

Results

During nCPAP, the MFF presented significantly lower values of $\triangle$ Pawi and $\triangle$ Pawe compared to the other interfaces tested (H and RFF). During NIV, the MFF demonstrated a better patient-ventilator interaction compared to RFF, as shown by significantly shorter Time press $_{\text {and Delay }}$ trexp $(p<0.01)$, but no significant

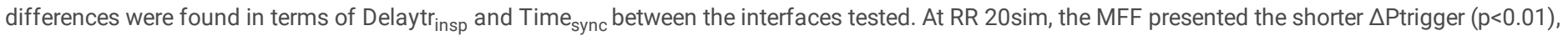
moreover during all the conditions tested the MFF showed the longer PTP 200, 300 and 500 compared to RFF ( $p<0.01$ ). A major limitation of MFF is that during NIV with this interface it is possible to reach at maximum $18 \mathrm{cmH}_{2} \mathrm{O}$ of peak inspiratory pressure. Over this pressure value, the presence of air leaks determined important asynchrony phenomena. For this reason, our test was limited to one pressure support and PEEP set $\left(\mathrm{PS} 10 \mathrm{cmH}_{2} \mathrm{O}\right.$ and $\left.\mathrm{PEEP} 8 \mathrm{cmH}_{2} \mathrm{O}\right)$.

Conclusions

The modified full face snorkeling mask can be used as an acceptable alternative to other interfaces for both nCPAP and NIV in emergency situations.

\section{Introduction}

On March 2020, the World Health Organization (WHO) declared the severe acute respiratory syndrome coronavirus 2 (SARS-CoV-2) outbreak a pandemic, due to the increasing number of cases reported worldwide ${ }^{1}$, with high rates of hospitalization and ICU admission ${ }^{2}$. The high number of SARS-CoV-2 cases initially in Lombardy, and subsequently throughout the whole country, made Italy one of the most affected country in Europe ${ }^{3}$.

As happened in March 2020, where in Lombardy in few days a total of 1593 patients, affected by severe respiratory failure due to COVID-19, were admitted to the ICU ${ }^{4}$, out of a total of 1202 ICU beds available ${ }^{2}$, the National health care system is now again under pressure from a growing second wave of patients hospitalized or admitted to ICU for acute respiratory failure .

COVID-19 is characterized by a viral interstitial pneumonia ${ }^{5}$ with fever, dry cough, dyspnoea, and bilateral ground-glass opacities ${ }^{6}$, with about $67 \%$ of patients evolving to a severe pneumonia ${ }^{7,8}$.

Preliminary reports described that COVID-19 patients, compared to conventional Acute Respiratory Distress Syndrome (ARDS), are characterized by moderate to severe hypoxemia despite a relatively high pulmonary compliance ${ }^{9,10}$. Due to the enormous number of COVID-19 patients with acute respiratory failure and to the shortage of ICU beds and ventilators, in many Italian hospital the management of patients with respiratory failure was entrusted to Non-Invasive Ventilation (NIV) or Non-invasive continuous positive airway pressure (nCPAP).

In particular, in a scenario of discrepancy between facilities and a large number of casualties, as with COVID-19 pandemic, the application of NIV or nCPAP has been useful as respiratory supportive strategy, especially in patients with mild to moderate $\mathrm{ARDS}$ and a $\mathrm{PaO}_{2}$ to Inspired oxygen fraction ratio $\left(\mathrm{PaO}_{2} / \mathrm{FiO} \mathrm{O}_{2}\right)$ $>150$. In our country, the Helmet ${ }^{4,10}$ has been the most widely used device for non-invasive respiratory support during COVID-19 outbreak both in general wards and in ICU ${ }^{10}$.

Unfortunately, a major problem of ventilator and device for NIV shortages rapidly emerged because of the further spread of the virus in other regions of Italy. In order to relieve the pressure on our national Health System, a device converting a full face snorkeling masks into a mask for CPAP or NIV has been designed and proposed for clinical use, with the help of 3D printers.

Given the large diffusion of this modified full face snorkeling mask in COVID-19 patients, we designed this bench study to evaluate and compare a helmet, a full face mask and a modified full face snorkeling mask in delivering nCPAP, and a modified full face snorkeling masks and a full face mask in delivering NIV in Pressure Support Ventilation mode (PSV).

\section{Materials And Methods}

The study was performed at the Respiratory Mechanics Lab (Ventilab) of the Fondazione Policlinico Universitario A. Gemelli IRCCS, Università Cattolica del Sacro Cuore in Rome, Italy.

\section{Bench Study}

Page $2 / 11$ 
Non-invasive CPAP and non-invasive positive pressure ventilation delivered in PSV mode were applied to a mannequin (LaerdalMedical AS, Stavanger, Norway) connected to an active test lung system (ASL 5000; Ingmar Medical, Pittsburgh, PA) set using a single-compartment model, an active inspiration simulated by a semi-sinusoidal pressure waveform (Rise Time $15 \%$, Pause $0 \%$ and Release Hold $25 \%$ ) and the following mechanical properties of the respiratory system : resistance $5 \mathrm{cmH}_{2} \mathrm{O} / \mathrm{l} / \mathrm{s}$ and compliance $40 \mathrm{ml} / \mathrm{cmH}_{2} \mathrm{O}$.

nCPAP was applied via Helmet (H) (CPAP-Castar Starmed, Mirandola, Italy), PerforMax Full face mask (Philips Respironics, Murrysville, PA, USA) (RFF) and a modified full face snorkeling mask (MFF)(SEA VU DRY, Mares Spa, Rapallo, Italy), while non-invasive PSV was delivered through RFF and MFF. The Helmet used for this bench study is a transparent latex-free polyvinylchloride hood, joined by a rigid plastic ring to a soft collar and secured by two padded armpit braces at four hooks (two in the front and two in the back of the plastic ring). The helmet used was the size Small to attain a good seal and avoid air-leaks.

The modifed full face snorkeling mask differs from Performax full face mask for shape and design characteristic; it presents a complete separation between inspiratory and expiratory circuits with the following main features: hypoallergenic silicone mouth-and-nose pocket connected to a polycarbonate transparent main body; quick-release buckles for easy doffing and a polycarbonate Charlotte valve with an inspiratory and an expiratory channel. See figure 1 for details.

MFF presents two parallel connections with a complete separation between inspiratory and expiratory limbs, while Performax Full face mask is characterized by a single limb connected to the $Y$ piece. The measure of masks used were medium size for RFF and large size for MFF to attain a good seal and avoid airleaks.

nCPAP $\left(10 \mathrm{cmH}_{2} \mathrm{O}\right)$ was applied at a simulated respiratory rate (RRsim) of 20 breaths per $\mathrm{min}(\mathrm{b} / \mathrm{min})$ and a simulated level of inspiratory effort (Pmus) of 12 $\mathrm{cmH}_{2} \mathrm{O}$, using a standard CPAP device delivering a flow rate of $60 \mathrm{l} / \mathrm{min}$ with reservoir (Drager CF 800 Continous Flow CPAP System; Dragerwerk AG \& Co, Lubeck, Germany).

NIV in PSV mode was delivered at 2 RRsim (20 and $30 \mathrm{~b} / \mathrm{min}$ ) and a Pmus of $12 \mathrm{cmH}_{2} \mathrm{O}$ with the mechanical ventilator (Puritan Bennet 840 ; Covidien HealthCare, Mansfield, MA) set in inspiratory pressure support (iPS) of $10 \mathrm{cmH}_{2} \mathrm{O}$, Positive End-Expiratory Pressure (PEEP) of $8 \mathrm{cmH} \mathrm{H}_{2} \mathrm{O}$, the fastest rate of pressurization, and a cycling-off flow threshold of 25 and $50 \%$ of the peak inspiratory flow. We set the inspiratory flow trigger at the lowest value not determining auto-cycling: this threshold was $5 \mathrm{~L} / \mathrm{min}$ during all conditions tested. This setting was chosen for comparing the performance of these interface under condition of highest pressurization rate and fast or slow cycling-off criteria ${ }^{11}$.

\section{Measurements}

Air flow (V') was measured with a pneumotachograph (Fleish No.1, Metabo, Epalinges, Switzerland), while airway pressure (Paw) was measured by a pressure transducer with a differential pressure of $\pm 100 \mathrm{cmH} 20$ (Digima Clic-1, ICULab system; KleisTek Engineering, Bari, Italy), placed distally from the pneumotachograph. Airflow $\left(V^{\prime}\right)$ and airway pressure (Paw) at the helmet inlet during the inspiratory phase were measured using a pneumotachograph (Fleisch n.2; Metabo, Epalinges, Switzerland) and a pressure transducer with differential pressure of $\pm 100 \mathrm{cmH}_{2} \mathrm{O}$ (Digima Clic-1; KleisTEK, ICU-Lab System, Italy) sited at the distal end of the inspiratory limb of the circuit. When the mannequin was ventilated through the RFF, the pneumotachograph and the pressure transducer were positioned at the Y-connection of the ventilator circuit, instead when we tested the MFF the pneumotachograph and the pressure transducer were positioned on the inspiratory channel. All these signals were acquired, amplified, filtered, digitized at $100 \mathrm{~Hz}$, recorded on a dedicated personal computer, and analyzed with a specific software (ICU lab 2.3; KleisTEK Advanced Electronic System, Italy and Analysis Plus).

Each trial lasted 5 minutes; the breaths of the last minute (20 or 30 depending on the trial) were recorded and averaged for analysis.

The measured variables assessed during nCPAP were the maximum inspiratory deflection ( $\triangle$ Pawi, inspiratory drop) and the expiratory peak ( $\triangle$ Pawe), calculated as differences from the preset CPAP level.

During the NIV test, we evaluated the following variables: Ventilator inspiratory and expiratory time (mechanical TI and mechanical TE, respectively), and ventilator rate of cycling were all determined on the flow tracing. The inspiratory duty cycle (mechanical $\mathrm{Tl} / \mathrm{Ttot}$ ) was calculated as the ratio between mechanical TI and the total mechanical breath duration (Ttot). Airflow (V') and tidal volume (VT) delivered to the simulator, airway opening pressure (Paw), and inspiratory muscles effort were displayed online on the computer screen. The signals obtained with the ASL were transmitted to a PC host via 10/100MBit Ethernet, sampled and processed in real time by means of specific software (Lab View, Ingmar Medical). The signals obtained with the ASL were integrated with the signals from the ICULab system by using a specific application of the ICULab (ICULab 2.7, KleisTek). The numerical integration of flow over time determined the mechanical tidal volume (mechanical VT). The amount of tidal volume delivered to the simulator during its active inspiration (ie, the neural tidal volume, $\mathrm{VT}_{\text {neu }}$ ) was calculated as the volume generated from the onset of inspiratory muscle effort negative deflection to its nadir.

Interfaces performance was evaluated using the following parameters ${ }^{11-13}$ :

1)Trigger pressure drop ( $\triangle$ Ptrigger), defined as the pressure swing generated by the simulator inspiratory effort in the airway during the triggering phase; 2 ) Inspiratory pressure-time product (PTPtrigger), defined as the area under the Paw curve relative to the time between the onset of inspiratory effort and the start of mechanical assistance; 3) pressure-time product at $200 \mathrm{~ms}$ from the onset of the ventilator pressurization (PTP200), as the index of pure pressurization performance ${ }^{14}$; 4)Pressure-time product at 300 ms (PTP300) defined as the integration of Paw over time during the first 300 msec and representing the speediness of the ventilator in reaching the preset level of pressure support; 5) Pressure-time product at 500 ms (PTP500), defined as the integral Paw area over insufflation time from the simulated effort onset, representing the ventilator capability of maintaining the pressurization; 6) PTP500 ideal index, expressed as a percentage of the ideal PTP, which is unattainable because it would imply a trigger pressure drop and an instantaneous pressurization of the ventilator. 
Patient-ventilator interaction was evaluated by determining:

1) Pressurization time (Time press $_{\text {) }}$, defined as the time necessary to achieve the pre-set level of pressure support from the baseline value; 2 ) Inspiratory trigger delay $\left(\right.$ Delaytr $\left._{\text {insp }}\right)$, calculated as the time lag between the onset of inspiratory muscle effort negative swing and the start of the ventilator support (i.e., Paw

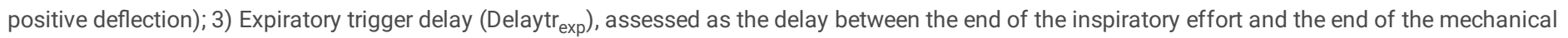
insufflations (i.e., flow deflection); 4) Time of synchrony (Time sync ), defined as the time during which inspiratory muscle effort and Paw are in phase (ideally $100 \%)$; 5) SimulatorVT/mechanicalVT, intended as the percentage of VT delivered during inspiratory muscle effort negative deflection; 6) The time during which simulator respiratory effort and ventilator assistance were synchronous, indexed to simulated inspiratory time ( $\left(\mathrm{Time}_{\text {sync }} / \mathrm{Ti}_{\text {neu }}\right)$ was also computed ${ }^{15}$ -

17.7) Wasted efforts, defined as ineffective inspiratory efforts, not assisted by the ventilator; 8) Auto-triggering, namely a mechanical insufflation in absence of inspiratory effort.

\section{Statistical analysis}

Continuous data were expressed as mean \pm standard deviation (SD). Categorical data were presented as number and percentage in brackets. All variables were compared with each interface used. Comparison were made by Student's $t$-test and Chi test, as appropriate. The analysis of variance (ANOVA) for repeated measures was used to detect significant differences between the different experimental conditions. When significant differences were detected, posthoc analysis was performed using the Bonferroni test; $p$ values $<0.05$ were considered statistically significant. Statistical analysis was performed using MEDcalc version 18.6 .

\section{Results}

As shown in Fig.2, during nCPAP, the MFF demonstrated significantly lower $\triangle$ Pawi and $\triangle$ Pawe values, compared to $\mathrm{H}$ and RFF ( $\mathrm{p}<0.01$ ). Of note, the differences between $\mathrm{H}$ and $\mathrm{RFF}$, in terms of $\triangle \mathrm{Pawi}$ and $\triangle \mathrm{Pawe}$, although statistically significant, were overall small and of limited clinical relevance.

Patient-ventilator interaction described by the measurement of Delaytr ${ }_{\text {insp, }}$ Time $_{\text {press }}$ and Delaytr ${ }_{\text {exp }}$ during NIV delivered through MFF and RFF are shown in Fig 3 and 4. At both RRsim tested and both ventilator settings, the MFF showed a significantly shorter Time press and Delaytr ${ }_{\text {exp }}$ compared to RFF ( $<<0.01$ ). During all conditions, no significant differences were found in terms of Delaytr ${ }_{\text {insp }}$, $\operatorname{Time}_{\text {sync }}$ (Fig. 4) and Time synch $/ \mathrm{Ti}_{\text {neu }}$ between all the interfaces tested. During all study conditions, the volume delivered with MFF was higher than that delivered with the RFF $(p<0.01)($ Table 1).

The trigger and pressurization performances of the two masks during NIV are shown in Tables 2 and 3. At RRsim 20, the MFF showed a significantly shorter $\triangle$ Ptrigger than RFF $(p<0.01)$, while no difference was found at RRsim 30. No significant differences were found in terms of PTPtrigger between the interfaces during all tested conditions.

Significant differences in PTP 200, PTP 300 and PTP 500 were found between MFF and RFF $(p<0.01)$ in all conditions tested. The MFF demonstrated a significantly higher capacity to maintain the pressurization at 200, 300 and 500 ms after opening the inspiratory valve.

In terms of PTP 500 ideal index, the MFF showed a higher value compared to RFF during all settings, although not statistically significant. During all settings, no asynchrony phenomena were detected with both interfaces.

During NIV test, with the MFF was possible to reach at maximum $18 \mathrm{cmH}_{2} \mathrm{O}$ of peak inspiratory applied pressure. Over this pressure, the presence of air leaks determined important asynchrony phenomena (as autocycling and double triggering), not modifiable with change in flow or pressure trigger.

\section{Discussion}

In this bench study, during nCPAP, the modified full face snorkeling mask presented a best performance compared to the other interfaces tested. Instead, during NIV, the MFF outperformed the RFF for most of the variables considered and in most of the simulated settings.

During the recent SARS-CoV-2 pandemic, an early non-invasive respiratory support allowed to treat a large number of patients with respiratory distress in order to prevent ICU admission. For several reasons the CPAP application by Helmet represented the first choice of treatment in patients with mild to moderate ARDS COVID-19 related. The Helmet demonstrated to be an effective alternative to face mask in recruiting alveolar units and improve hypoxemia. It can also limit airleaks and room contamination, increasing patient's comfort, and is more tolerated than the face mask requiring fewer discontinuations ${ }^{10,18,19}$.

Unfortunately, the enormous request for helmet CPAP resulted in a rapid lack of supply, so many laboratories, in order to try to fill this gap, started to readjust snorkeling masks into devices for respiratory support.

We therefore decided to compare the modified snorkeling mask with the Helmet and one of the most popular full face mask (PerforMax full face mask), during CPAP. We applied CPAP at $10 \mathrm{cmH}_{2} \mathrm{O}$ because this is a value most commonly applied in this clinical setting ${ }^{20,21}$.

In our nCPAP bench study evaluation, the MFF presented significantly lower values of $\triangle \mathrm{Pawi}$ and $\triangle \mathrm{Pawe}$ compared to the other interfaces tested, showing a minor depressurization during the inspiratory and expiratory phases. These results suggest an increased stability in maintaining the PEEP level applied during nCPAP. Probably, this phenomenon may be due to the low internal volume of MFF, due to the presence of the so-called mouth-and-nose pocket, that reduces the mask internal volume. In fact, the MFF total internal volume is $1350 \mathrm{ml}$, but the mouth-and-nose pocket internal volume is only $80 \mathrm{ml}$, while the RFF internal volume is $500 \mathrm{ml}$ and the $\mathrm{H}$ internal volume is $15000 \mathrm{ml}$ (a real pressurized gas reservoir during inspiration).

Page $4 / 11$ 
The MFF has been initially proposed as an alternative to the helmet for CPAP, but during the emergency it has been often used also for NIV. Therefore, we decided to compare this interface with one of the most popular interfaces used in ICU for NIV (RFF). We limited the comparison only to the RFF because, as previously demonstrated by Chiumello et al. ${ }^{22}$, in pressure support mode, the mask was more efficient than the helmet. In fact, with the helmet the initial part of the inspiratory pressure applied is dissipated to pressurize its soft wall. Accordingly, Navalesi et al. ${ }^{23}$ demonstrated that the helmet significantly worsens patient- ventilator synchrony, when compared to the facemask, as indicated by longer delays between inspiratory muscle effort and support delivery, both at the onset and at the end of inspiration, and by the occurrence of wasted efforts.

For NIV settings, the values of the simulated effort, RRsim, resistance, and compliance, were those already utilized in previous investigations ${ }^{24,25,26}$. The MFF

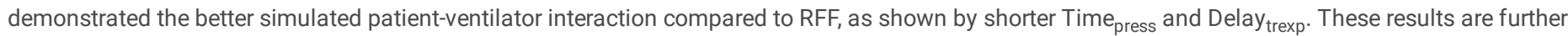
validated by interface performance data. Probably the better performance underlined by shorter $\Delta$ Ptrigger, and longer PTP 200,300 and 500 can be explained by the reduced MFF inner volumes and its materials (Figure 1). In fact, a prerogative of this mask is the presence of two separate limbs. The fresh air enters through the snorkel's central channel, passing the lens, and keeping it fog-free. It then enters the oral-nasal pocket through non-return valves and flows towards the nose and mouth. The oral-nasal pocket's structure guides exhaled $\mathrm{CO} 2$ through 4 no-return valves:

- 2 no-return valves, one each side of the nose, to prevent backward flow,

- 2 no-return valves at the entrance of the exhalation tubes.

Exhaled $\mathrm{CO} 2$ is channeled into the soft silicone side tubes through the second pair of no-return valves. This configuration could explain our results in terms of simulated patient-ventilator interaction and performance device during NIV settings.

A major limitation of MFF must be underlined: during NIV with this interface it is possible to reach at maximum $18 \mathrm{cmH}_{2} \mathrm{O}$ of peak inspiratory applied pressure. Over this pressure, the presence of air leaks determines important asynchrony phenomena (as autocycling and double triggering), not modifiable with change in flow or pressure trigger. For this reason, our test was limited to a single pressure support and PEEP level $\left(\mathrm{PS} 10 \mathrm{cmH}_{2} \mathrm{O}\right.$ and PEEP $\left.8 \mathrm{cmH}_{2} \mathrm{O}\right)$.

\section{Conclusion}

The results of this comparative bench study suggest that this modified snorkeling mask can be used as an alternative to other interfaces for both CPAP and NIV in emergency situations. The MFF can be proposed in the event of new pandemic surge or for countries where the number of COVID-19 patients is such that all usable interfaces for non-invasive respiratory support must be used. Particular attention should be paid to the use of this modified snorkeling mask during NIV, related to the maximum pressure limit of $18 \mathrm{cmH}_{2} 0$.

\section{Abbreviations}

ICUs: Intensive Care Units; nCPAP: Non-invasive continuous positive airway pressure, NIV: Non-invasive ventilation; Pmus: Simulated effort; PSV: Pressure support ventilation; WHO: World Health Organization; ARDS: Acute respiratory distress syndrome; $\mathrm{PaO}_{2} / \mathrm{FiO} \mathrm{O}_{2}$ : Inspired oxygen fraction ratio; RRsim: Simulated respiratory rate; iPS: Inspiratory pressure support; $\triangle$ Pawi: Maximum inspiratory deflection; $\triangle$ Pawe: Expiratory peak; TI: Mechanical inspiratory time; TE: Mechanical expiratory time, VT: Tidal volume; $\mathrm{VT}_{\text {neu }}$ : Neural tidal volume; Ttot: Total mechanical breath duration; Paw: Airway opening pressure; $\Delta \mathrm{Ptrigger:}$ Trigger pressure drop; PTPt: Inspiratory pressure-time product; PTP: Pressure time product; Time $_{\text {press: }}$ Pressurization time; Delaytr ${ }_{\text {insp: }}$ Inspiratory trigger delay;

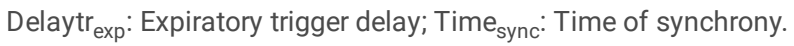

\section{Declarations}

\section{Acknowledgements}

The authors are grateful to all ICU doctors, residents, and nurses who fight this COVID 19 pandemia with their efforts and passion.

\section{Authors' contributions}

GF, AG, AS, GS and GC conceived the study. GF, GS, AS, AG and EP conducted the bench study. GF and GS analyzed the data. GF, GS and GC interpreted the data and wrote the first draft of the manuscript. GC and MA critically revised the manuscript. All the authors reviewed the final draft of the manuscript and agreed on submitting it to the Critical Care.

\section{Funding}

This study was funded solely by institutional/departmental resources.

\section{Availability of data and materials}

The datasets used and/or analyzed during the current bench study are available from the corresponding author on reasonable request.

\section{Ethics approval and consent to participate}

Not applicable

\section{Consent for publication}


Not applicable

\section{Competing interests}

The authors declare that they have no competing interests

\section{References}

1. WHO Director-General' s opening remarks at the media briefing on COVID-19:11 March 2020. Published March 11, 2020. Accessed March 30, 2020. https://www.who.int/dg/speeches/detail/who-director-general-s-opening-remarks-at-themedia-briefing-on-covid-19--11-march-2020

2. Grasselli G, Pesenti A, Cecconi M. Critical care utilization for the COVID-19 outbreak in Lombardy, Italy: early experience and forecast during an emergency response. JAMA. 2020; 323(16):1545-1546.

3. Coronavirus COVID-19 global cases by the Center for Systems Science and Engineering (CSSE) at Johns Hopkins. Up dated March 30, 2020. Accessed March 30, 2020.

4. Grasselli G, Zangrillo A, Zanella A, Antonelli M, Cabrini L et al. Baseline Characteristics and Outcomes of 1591 Patients Infected With SARS-CoV-2 Admitted to ICUs of the Lombardy Region, Italy. 2020; 323(16):1574-81.

5. Shi Y, Wang Y, Li X, Huang J, Gan J, Huang X et al. Covid 19 infection: the perspectives on immune response. Cell Death Differ. 2020; 27(5):1451-1454.

6. Huang C, Wang Y, Li X, Lili Ren, Jianping Zhao, Yi Hu et al. Clinical features of patients affected with 2019 novel coronavirus in Wuhan, China. Lancet. 2020; 395: 497-506.

7. Yang X, Yu Y, Shu H, Shu H, Xia J, Liu H et al. Clinical course and outcomes of critically ill patients with Sars-CoV2 pneumonia in Whuan, China: a single centered, retrospective, observational study. Lancet Respir Med. 2020; 8(5):475-481.

8. Bhrataju PK, Ghassemieh BJ, Nichols M, Kim R, Jerome KR, Nalla AH et al. Covid-19 in critically ill patients in the seattle region-case series. N Eng J Med. 2020; 382(21):2012-2022.

9. Gattinoni L, Coppola S, Cressoni M, Busana M, Rossi S and Chiumello D. Covid-19 does not lead to "typical" acute respiratory distress syndrome. Am J Respir Crit Care Med. 2020; 201(10):1299-1300.

10. Lucchini A, Giani M, Isgro S, Rona R and Foti G. The "helmet bundle" in COVID-19 patients undergoing non invasive ventilation. Intensive Crit Care Nurs. 2020; 58:102859

11. Olivieri C, Costa R, Spinazzola G, Ferrone G, Longhini F, Cammarota G et al. Bench comparative evaluation of a new generation and standard helmet for delivering non-invasive ventilation. Intensive Care Med. 2013; 39:734-8.

12. Vignaux L, Vargas F, Roeseler J, Tassaux D, Thille AW, Kossowsky MP et al. Patient-ventilator asynchrony during non-invasive ventilation for acute respiratory failure: a multicenter study. Intensive Care Med. 2009; 35:840. 21.

13. Vignaux L, Piquilloud L, Tourneux P, Jolliet P and Rimensberger PC. Neonatal and adult ICU ventilators to provide ventilation in neonates, infants, and children: a bench model study. Respir Care. 2014; 59:1463-75. 22.

14. Olivieri C, Costa R, Conti G, Navalesi P. Bench studies evaluating devices for non-invasive ventilation: critical analysis and future perspectives. Intensive Care Med. 2012; 38:160-167.

15. Cammarota G, Longhini F, Perucca R, Ronco C, Colombo D, Messina A et al. New setting of neurally adjusted ventilatory assist during noninvasive ventilation through a helmet. Anesthesiology 2016; 125 (6):1181-9.

16. Olivieri C, Longhini F, Cena T, Cammarota G, Vaschetto R, Messina A et al. New versus conventional helmet for delivering noninvasive ventilation: a physiologic, crossover randomized study in critically ill patients. Anesthesiology. 2016; 124 (1):101-8.

17. Longhini F, Pan C, Xie J, Cammarota G, Bruni A, Garofalo E et al. New setting of neurally adjusted ventilatory assist for noninvasive ventilation by facial mask: a physiologic study. Crit Care. 2017; 21(1):170.

18. Antonelli M, Conti G, Pelosi P, Gregoretti C, Pennisi MA, Costa Ret al. New treatment of acute hypoxemic respiratory failure: noninvasive pressure support ventilation delivered by helmet: a pilot controlled trial. Crit Care Med. 2002; 30(3): 602-608.

19. Antonelli M, Pennisi MA, Pelosi P, Gregoretti C, Squadrone V, Rocco M et al. Noninvasive positive pressure ventilation using a helmet in patients with acute exacerbation of chronic obstructive pulmonary disease: a feasibility study. Anesthesiology. 2004;100 (1): 16-24.

20. Ferrari G, Oliveri F, De Filippi G, Apri F, Boccuzzi A, Converso M et al. Non-invasive positive airway pressure and risk of myocardial infarction in acute cardiogenic pulmonary edema: continuous positive airway pressure vs. non-invasive positive pressure ventilation. Chest. 2007; 132:1804-1809 19.

21. Cammarota G, Vaschetto R, Turucz E, Dellapiazza F, Colombo D, Blando C et al. Influence of lung collapse distribution on the physiologic response to recruitment maneuvers during noninvasive continuous positive airway pressure. Intensive Care Med. 2011; 37:1095-1102.

22. Chiumello D, Pelosi P, Carlesso E, Severgnini P, Aspesi M, Gamberoni C et al. Noninvasive positive pressure ventilation delivered by helmet vs standard face mask. Intensive Care Med. 2003; 29:1671-1679.

23. Navalesi P, Costa R, Ceriana P, Carlucci A, Prinianakis G, Antonelli M et al. Noninvasive ventilation in chronic obstructive pulmonary disease patients: helmet versus facial mask. Intensive Care Med. 2006; 33:74-81.

24. Costa R, Navalesi P, Spinazzola G, Rossi M, Cavaliere F, Antonelli M et al. Comparative evaluation of different helmets on patient-ventilator interaction during non-invasive ventilation. Intensive Care Med. 2008; 34:1102-1108 14.

25. Costa R, Navalesi P, Spinazzola G, Ferrone G, Pellegrini A, Cavaliere F et al. Influence of ventilator settings on patient-ventilator synchrony during pressure support ventilation with different interfaces. Intensive Care Med. 2010; 36:1363-1370.

Page 6/11 
26. Grasselli G, Tonetti T, Protti A, Langer T, Girardis M, Bellani G et al. Pathophysiology of COVID-19-associated acute respiratory distress syndrome: a multicentre prospective observational study. Lancet Respir Med. 2020 Aug 27: S2213-2600(20)30370-2.

\section{Tables}

Table 1: Tidal volume delivered with the different interfaces tested

\begin{tabular}{|c|c|c|c|c|c|c|}
\hline & $M F F$ & $R F F$ & & $M F F$ & $R F F$ & \\
\hline & $\begin{array}{l}\text { RR } 20 \\
\text { Timepress 100\%/Trexp50\% }\end{array}$ & $\begin{array}{l}\text { RR20 } \\
\text { Timepress } 100 \% / T r e x p 50 \%\end{array}$ & $P$ & $\begin{array}{l}R R 20 \\
\text { Timepress } 100 \% / T r e x p 25 \%\end{array}$ & $\begin{array}{l}\text { RR20 } \\
\text { Timepress } 100 \% / T r e x p 25 \%\end{array}$ & $P$ \\
\hline $\begin{array}{l}\text { VTmech } \\
(\mathrm{ml})\end{array}$ & $7.54 .33 \pm 5.77$ & $676 \pm 0.00$ & 0.001 & $8.14 .33 \pm 5.77$ & $694 \pm 0.00$ & 0.001 \\
\hline $\begin{array}{l}\text { VTneu } \\
\text { (ml) }\end{array}$ & $606.33 \pm 5.77$ & $459 \pm 5.20$ & 0.001 & $603 \pm 0.00$ & $459 \pm 5.2$ & 0.001 \\
\hline \multirow{3}{*}{$\begin{array}{l}\text { VTneu/VTmech } \\
\text { (\%) }\end{array}$} & $80 \%$ & $68 \%$ & 0.001 & $74 \%$ & $66 \%$ & 0.001 \\
\hline & $M F F$ & $R F F$ & & MFF & $R F F$ & \\
\hline & $\begin{array}{l}\text { RR } 30 \\
\text { Timepress } 100 \% / T r e x p 50 \%\end{array}$ & $\begin{array}{l}\text { RR30 } \\
\text { Timepress } 100 \% / T r e x p 50 \%\end{array}$ & $P$ & $\begin{array}{l}\text { RR } 30 \\
\text { Timepress100\%/Trexp25\% }\end{array}$ & $\begin{array}{l}\text { RR30 } \\
\text { Timepress100\%/Trexp25\% }\end{array}$ & $P$ \\
\hline $\begin{array}{l}\text { VTmech } \\
(\mathrm{ml})\end{array}$ & $724.33 \pm 5.77$ & $586 \pm 5.2$ & 0.001 & $739.67 \pm 6.35$ & $566.33 \pm 5.77$ & 0.001 \\
\hline $\begin{array}{l}\text { VTneu } \\
(\mathrm{ml})\end{array}$ & $417.33 \pm 5.77$ & $304 \pm 9.00$ & 0.001 & $378 \pm 0.00$ & $276 \pm 0.00$ & 0.001 \\
\hline $\begin{array}{l}\text { VTneu/VTmech } \\
\text { (\%) }\end{array}$ & $58 \%$ & $52 \%$ & 0.001 & $51 \%$ & $49 \%$ & 0.02 \\
\hline
\end{tabular}

$\mathrm{VT}_{\text {mech: }}$ : mechanical tidal volume; $\mathrm{VT}_{\text {neu }}$ : neural tidal volume; $\mathrm{VT}_{\text {neu }} / \mathrm{VT}_{\text {mech }}$ : the percentage of tidal volume delivered during inspiratory simulated muscle effort negative deflection.

MFF: Modified Mares Full Face Mask, RFF: Respironics PerforMax Full face mask.

$R R$ Respiratory rates.

Table 2: Performance of the interfaces during NIV at 20 RRsim

\begin{tabular}{|c|c|c|c|c|c|c|}
\hline & MFF & $R F F$ & & MFF & $R F F$ & \\
\hline & $\begin{array}{l}\text { RR } 20 \\
\text { Timepress 100\%/Trexp50\% }\end{array}$ & $\begin{array}{l}\text { RR20 } \\
\text { Timepress } 100 \% / \text { Trexp } 50 \%\end{array}$ & $P$ & $\begin{array}{l}R R 20 \\
\text { Timepress100\%/Trexp25\% }\end{array}$ & $\begin{array}{l}\text { RR20 } \\
\text { Timepress100\%/Trexp25\% }\end{array}$ & $P$ \\
\hline $\begin{array}{l}\Delta \text { Ptrigger } \\
\left(\mathrm{cmH}_{2} \mathrm{O}\right)\end{array}$ & $1.05 \pm 0.01$ & $0.72 \pm 0.05$ & 0.004 & $1.03 \pm 0.05$ & $0.78 \pm 0.04$ & 0.014 \\
\hline $\begin{array}{l}\text { PTPt } \\
\left(\mathrm{cmH}_{2} \mathrm{O} / \mathrm{s}\right)\end{array}$ & $0.04 \pm 0.01$ & $0.03 \pm 0.01$ & 1 & $0.05 \pm 0.00$ & $0.03 \pm 0.00$ & 0.001 \\
\hline $\begin{array}{l}\text { PTP200 } \\
\left(\mathrm{cmH}_{2} \mathrm{O} / \mathrm{s}\right)\end{array}$ & $0.88 \pm 0.05$ & $0.57 \pm 0.09$ & 0.013 & $0.87 \pm 0.12$ & $0.57 \pm 0.05$ & 0.04 \\
\hline $\begin{array}{l}\text { PTP300 } \\
\left(\mathrm{cmH}_{2} \mathrm{O} / \mathrm{s}\right)\end{array}$ & $2.04 \pm 0.08$ & $1.22 \pm 0.09$ & 0.004 & $1.97 \pm 0.03$ & $1.21 \pm 0.05$ & 0.001 \\
\hline $\begin{array}{l}\text { PTP500 } \\
\left(\mathrm{cmH}_{2} \mathrm{O} / \mathrm{s}\right)\end{array}$ & $4.49 \pm 0.09$ & $2.66 \pm 0.11$ & 0.001 & $4.35 \pm 0.03$ & $2.67 \pm 0.03$ & 0.001 \\
\hline $\begin{array}{l}\text { PTP500 ideal } \\
\text { index }(\%)\end{array}$ & 72 & 56 & 0.45 & 71 & 51 & 0.5 \\
\hline
\end{tabular}


$\triangle$ Ptrigger: trigger pressure drop, PTPt. Pressure Time Product during the triggering phase, Paw: airway pressure, PTP200, PTP300 and PTP500: Pressure Time Product during the initial 200, 300 and 500 ms from the onset of the ventilator pressurization expressed as the absolute value, PTP500 ideal index: Pressure Time Product during the initial $500 \mathrm{~ms}$ from the onset of the simulated effort, expressed as the percentage of the area of ideal pressurization, with different ventilator settings (see text).

MFF: Modified Mares Full Face Mask, RFF: Respironics PerforMax Full face mask.

$R R$ Respiratory rates.

Table 3:Performance of the interfaces during NIV at 30 RRsim

\begin{tabular}{|c|c|c|c|c|c|c|}
\hline & MFF & $R F F$ & & MFF & $R F F$ & \\
\hline & $R R 30$ & \multirow{2}{*}{$\begin{array}{l}\text { RR30 } \\
\text { Timepress } 100 \% / T r e x p 50 \%\end{array}$} & \multirow[t]{2}{*}{$P$} & $R R 30$ & \multirow{2}{*}{$\begin{array}{l}\text { RR30 } \\
\text { Timepress } 100 \% / T r e x p 25 \%\end{array}$} & \multirow[t]{2}{*}{$P$} \\
\hline & Timepress $100 \% /$ Trexp $50 \%$ & & & Timepress100\%/Trexp25\% & & \\
\hline $\begin{array}{l}\Delta \text { Ptrigger } \\
\left(\mathrm{cmH}_{2} \mathrm{O}\right)\end{array}$ & $1.28 \pm 0.04$ & $1.75 \pm 0.47$ & 0.11 & $1.94 \pm 0.23$ & $2.05 \pm 0.11$ & 0.31 \\
\hline $\begin{array}{l}\text { PTPt } \\
\left(\mathrm{cmH}_{2} \mathrm{O} / \mathrm{s}\right)\end{array}$ & $0.06 \pm 0.01$ & $0.10 \pm 0.04$ & 0.12 & $0.11 \pm 0.02$ & $0.13 \pm 0.01$ & 0.16 \\
\hline $\begin{array}{l}\text { PTP200 } \\
\left(\mathrm{cmH}_{2} \mathrm{O} / \mathrm{s}\right)\end{array}$ & $0.98 \pm 0.07$ & $0.56 \pm 0.10$ & 0.02 & $0.63 \pm 0.15$ & $0.32 \pm 0.03$ & 0.04 \\
\hline $\begin{array}{l}\text { PTP300 } \\
\left(\mathrm{cmH}_{2} \mathrm{O} / \mathrm{s}\right)\end{array}$ & $2.26 \pm 0.07$ & $1.29 \pm 0.10$ & 0.002 & $1.91 \pm 0.08$ & $1.07 \pm 0.10$ & 0.006 \\
\hline $\begin{array}{l}\text { PTP500 } \\
\left(\mathrm{cmH}_{2} \mathrm{O} / \mathrm{s}\right)\end{array}$ & $5.09 \pm 0.03$ & $3.05 \pm 0.12$ & 0.007 & $4.69 \pm 0.16$ & $2.77 \pm 0.11$ & 0.003 \\
\hline $\begin{array}{l}\text { PTP500 ideal } \\
\text { index (\%) }\end{array}$ & 71 & 56 & 0.22 & 68 & 48 & 0.3 \\
\hline
\end{tabular}

$\triangle$ Ptrigger: trigger pressure drop, PTPt. Pressure Time Product during the triggering phase, Paw: airway pressure, PTP200, PTP300 and PTP500: Pressure Time Product during the initial 200, 300 and 500 ms from the onset of the ventilator pressurization expressed as the absolute value, PTP500 ideal index: Pressure Time Product during the initial $500 \mathrm{~ms}$ from the onset of the simulated effort, expressed as the percentage of the area of ideal pressurization, with different ventilator settings (see text).

MFF: Modified Mares Full Face Mask, RFF: Respironics PerforMax Full face mask.

$R R$ Respiratory rates

\section{Figures}




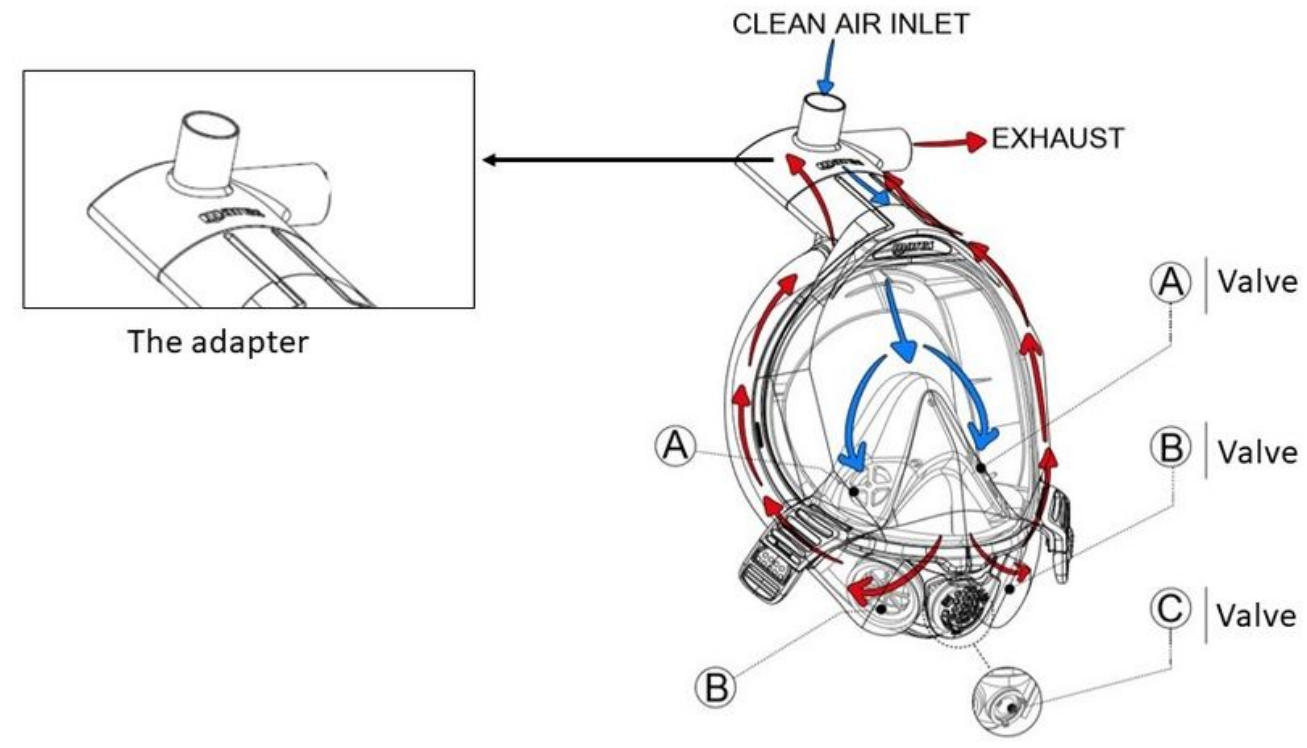

\section{Figure 1}

Mares snorkeling mask (MFF) features: presence of two separate limbs; the inspiratory one is highlighted by blue arrows, the expiratory one by red arrows. The adapter created with $3 \mathrm{~d}$ printers features two channels: the central upward-pointing channel is the inspiratory channel, the side channel is the expiratory channel.

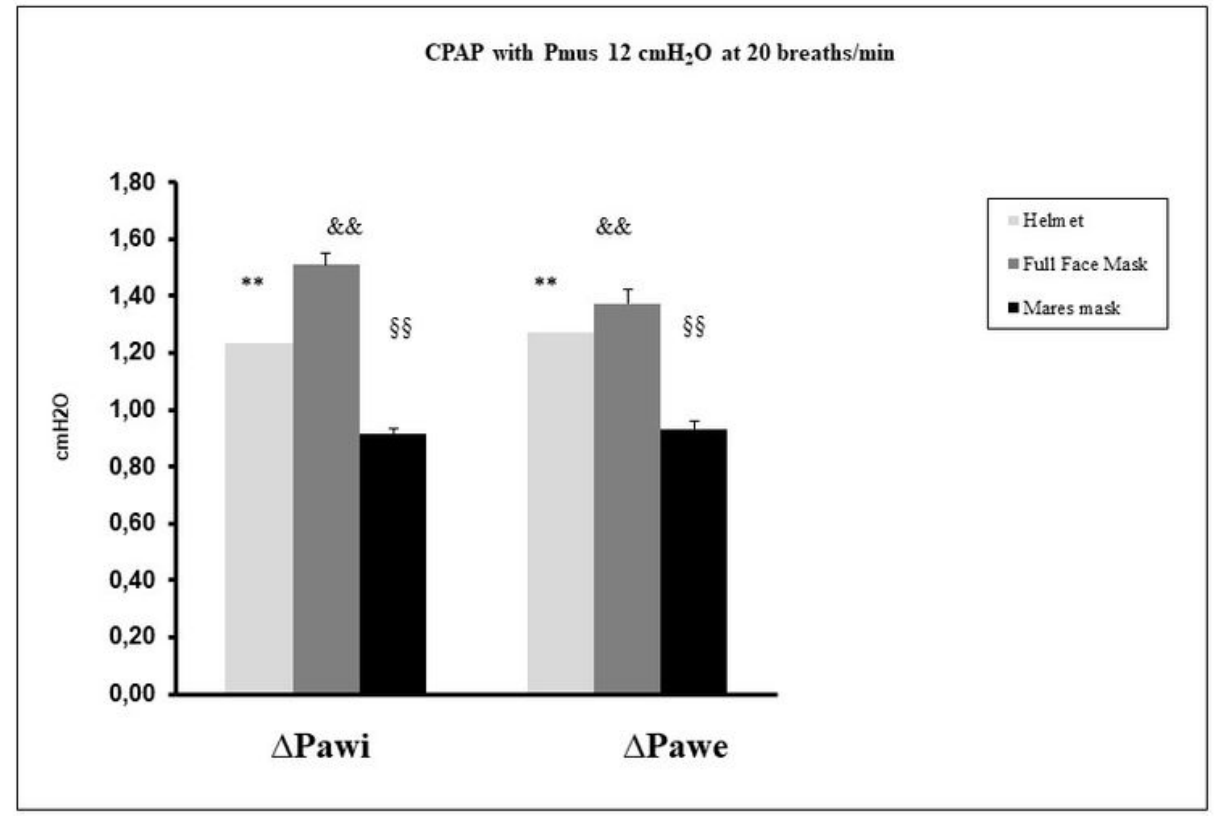

*= Helmet vs Full Face mask

$\&=$ Helmt vs Mares mask

$\S=$ Full Face mask vs Mares mask

$*, \S, \&=p<0.05$

$* *, \S \S, \& \& \&=p<0.01$ 
Maximum inspiratory deflection ( $\triangle$ Pawi, inspiratory drop) and the expiratory peak ( $\triangle$ Pawe), during CPAP with Helmet (light grey column), PerforMax Full face mask (dark grey column) and Mares Mask (black column) at 20 breaths/min.

\section{Patient-ventilator interaction at 20 breaths/min}

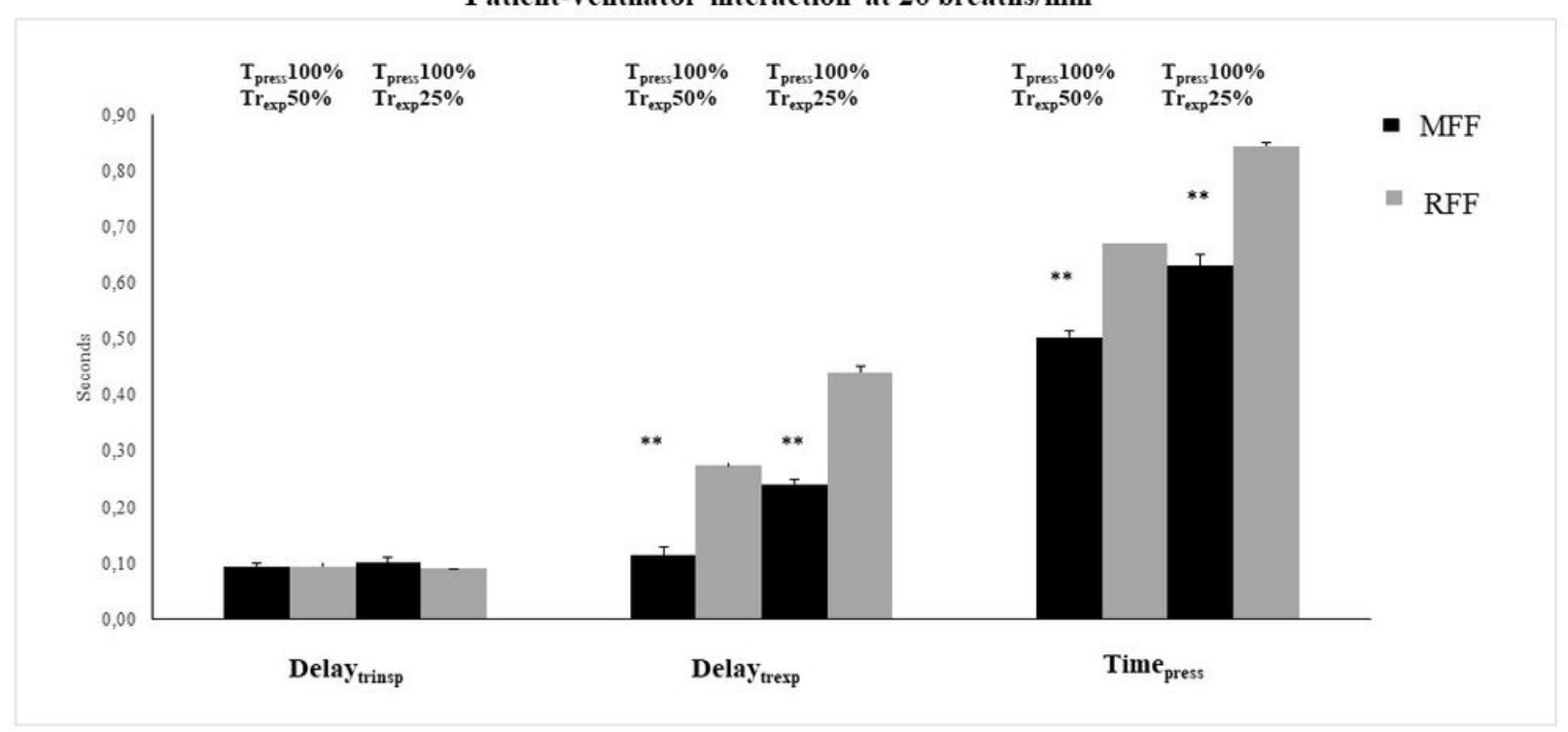

MFF vs RFF: *

$* *=p<0.01$

\section{Figure 3}

Inspiratory trigger delay (Delaytrinsp), Expiratory Trigger delay (Dealytrexp), and Pressurization Time (Timepress) with the Mares Mask (MFF) (black column) and the PerforMax Full face mask (RFF) (grey column) at 20 breaths/min, with 2 ventilator settings.

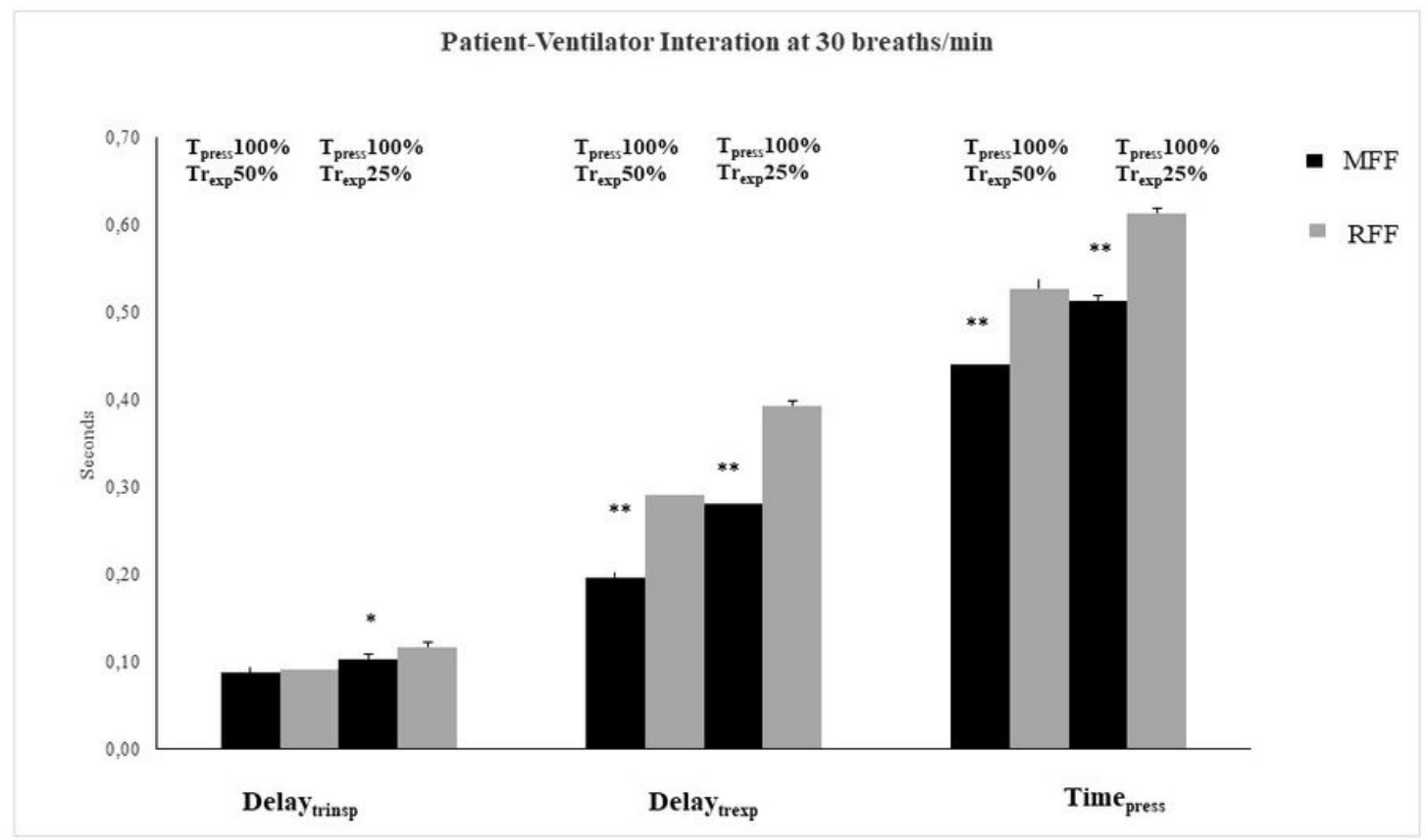


Figure 4

Inspiratory trigger delay (Delaytrinsp), Expiratory Trigger delay (Dealytrexp), and Pressurization Time (Timepress) with the Mares Mask (MFF) (black column) and the PerforMax Full face mask (RFF) (grey column) at 30 breaths/min, with 2 ventilator settings.
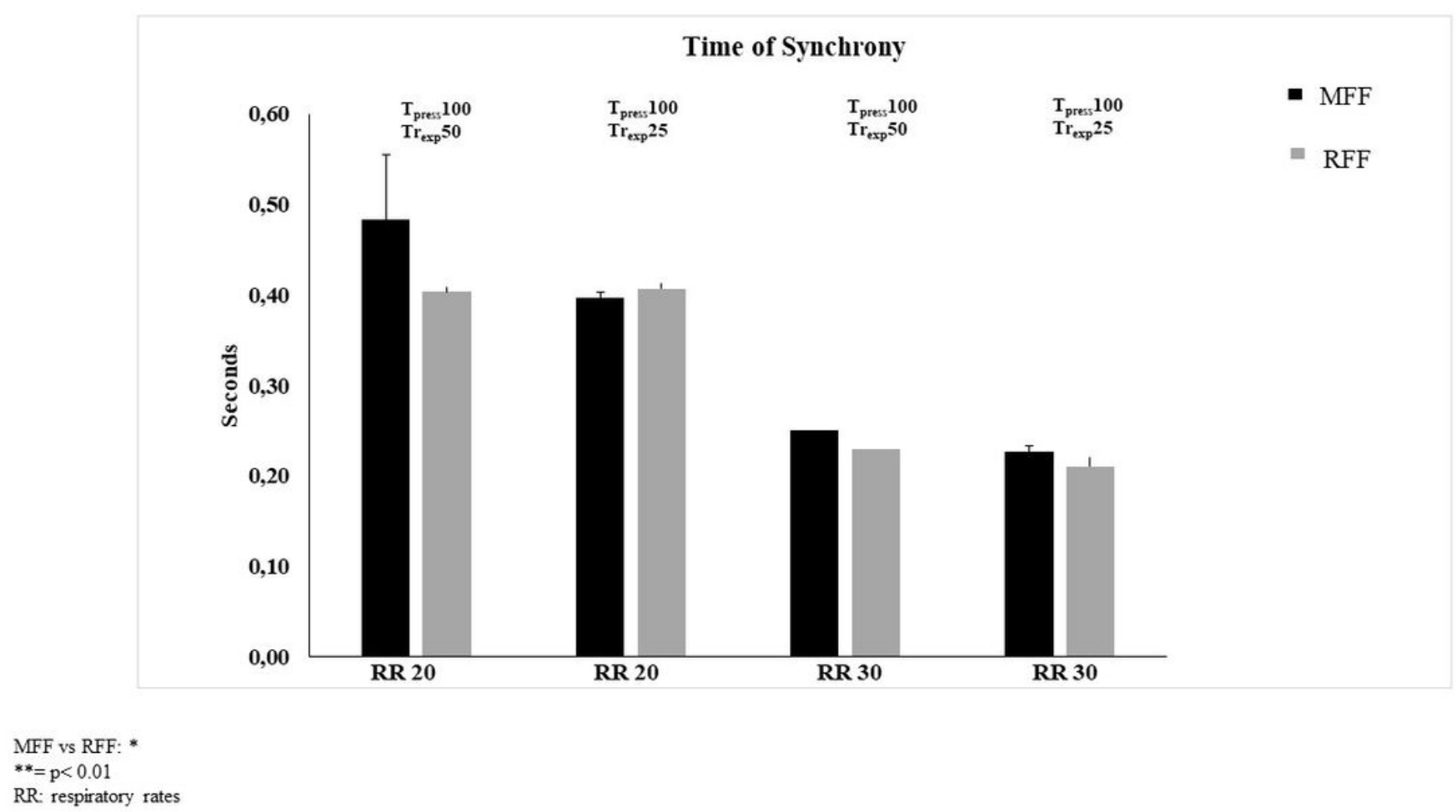

\section{Figure 5}

Time of synchrony with the Mares Mask (MFF) (black column) and the PerforMax Full face mask (RFF) (grey column) at two respiratory rates (RR 20 and 30 breaths/min), with 2 ventilator settings. 